\title{
Ambrogio A. CAIANI, Louis XVI and the French
}

Revolution 1789-1792

Cambridge, Cambridge University Press,[2012] 2013

Hélène Becquet

\section{(2) OpenEdition}

1 Journals

Édition électronique

URL : https://journals.openedition.org/ahrf/13116

DOI : 10.4000/ahrf.13116

ISSN : 1952-403X

Éditeur :

Armand Colin, Société des études robespierristes

\section{Édition imprimée}

Date de publication : 1 mars 2014

Pagination : 235-236

ISBN : 978-2-200-9083-2790-8

ISSN : 0003-4436

\section{Référence électronique}

Hélène Becquet, "Ambrogio A. caIANI, Louis XVI and the French Revolution 1789-1792 ", Annales

historiques de la Révolution française [En ligne], 375 | janvier-mars 2014, mis en ligne le 08 juillet 2014, consulté le 06 juillet 2021. URL : http://journals.openedition.org/ahrf/13116 ; DOI : https://doi.org/ 10.4000/ahrf.13116

Ce document a été généré automatiquement le 6 juillet 2021.

Tous droits réservés 


\title{
Ambrogio A. CAIANI, Louis XVI and the French Revolution 1789-1792
}

Cambridge, Cambridge University Press,[2012] 2013

\author{
Hélène Becquet
}

\section{RÉFÉRENCE}

Ambrogio A. CAIANI, Louis XVI and the French Revolution 1789-1792. Cambridge, Cambridge University Press,[2012] 2013, 254 p., ISBN 978-1-107-02633- 9, 31,22€.

1 Dressant le constat d'un vide historiographique sur le règne constitutionnel de Louis XVI et son système de représentation, Ambrogio A. Caiani se propose de prendre comme objet d'étude la cour de Louis XVI de 1789 à 1792 et de montrer comment celleci contribue à la radicalisation révolutionnaire et, finalement, à la chute de la monarchie. Compte tenu de l'état lacunaire des sources, l'auteur a préféré présenter une série d'études de cas plutôt qu'une étude systématique de son objet. Bien que compréhensible, ce choix laisse une impression de fragmentation excessive d'un discours par ailleurs intéressant.

2 La première partie "Inventer une monarchie constitutionnelle ", est divisée en trois chapitres. Le premier s'ouvre sur une narration revisitée de la fameuse altercation entre Dreux-Brézé et Mirabeau le 23 juin 1789. Cette scène montre bien en effet que le protocole de l'ancienne cour est impuissant à contrecarrer la nouvelle légitimité politique de l'Assemblée nationale. Le reste du chapitre sur le grand maitre des cérémonies et les hérauts d'armes est moins percutant. L'analyse du rôle du grand maître est succincte, voire inexacte sur la présentation du système des offices.

3 Le chapitre suivant est consacré à la mise en place de la liste civile qui fait du roi, premier fonctionnaire de l'État, un salarié. L'auteur montre bien qu'alors qu'elle était initialement conçue pour conserver au trône le prestige nécessaire, elle est la preuve en elle-même de l'abaissement de la condition royale, d'autant qu'elle ne s'accompagne pas de réformes structurelles de l'institution curiale. Suit l'analyse d'un texte de Sieyès, 
Qu'est-ce que le roi? , incontestablement intéressant, mais dont il faut relativiser le caractère exemplaire que lui confère Ambroggio Caiani pour les besoins de sa démonstration.

4 Dans le dernier chapitre de cette partie, l'auteur dresse une sorte de récit au jour le jour du rituel curial de 1789 à 1792 en s'appuyant sur les correspondances diplomatiques. La permanence et la tradition l'emportent sur la nouveauté alors même que le système politique a changé. Pour Caiani, le décalage entre les deux rend inefficient voir nuisible pour le régime le système de représentation monarchique.

La seconde partie "Réforme et survivance de l'Ancien Régime » est une série de quatre études de cas. La première concerne l'évolution du statut des troupes chargées de la protection du roi. Aux Tuileries, le service est partagé entre les restes de la maison militaire du roi et la garde nationale, non sans frictions et tensions. L'Assemblée nationale se méfie des gardes suisses et des gardes du corps soupçonnés de contrerévolution, tandis que le roi voit les membres de la garde nationale comme des geôliers. Pour apaiser les tensions, une garde constitutionnelle commence à être constituée dans l'année 1792, mais ne peut voir le jour.

6 L'auteur étudie ensuite la fin du système de présentation, en vigueur depuis Louis XV. Louis XVI refuse en effet de réformer le système en profondeur, en le fondant sur d'autres titres que ceux de la naissance, comme finira par le faire son frère en 1820 . Dans le même temps, conscient de son impopularité, il préfère renoncer à toute présentation à partir de 1791 .

7 Est abordée dans un troisième temps la question des ordres de chevalerie. Théoriquement abolis au mois d'août 1791, ils ne connaissent cependant pas tous exactement le même sort. L'Ordre de Saint-Michel, ouvert aux roturiers et aux anoblis, était un instrument de reconnaissance du talent et a connu des promotions importantes jusqu'en 1791. L'Ordre de Saint-Louis, ordre militaire fondé lui aussi sur le mérite, n'est pas supprimé en 1791. En revanche l'Ordre du Saint-Esprit, aristocrate dans son recrutement, lié à la religion royale, devient vite l'objet de vives critiques, qui poussent Louis XVI à ne plus y nommer qui que ce soit, tout en continuant à le tenir pour l'ordre de chevalerie le plus important du royaume.

8 Enfin, l'étude de la chapelle royale montre comment l'installation à Paris diminue, en raison des contraintes matérielles, l'importance des cérémonies religieuses à la cour. En outre, la constitution civile du clergé a des répercussions néfastes : une partie des clercs émigre et une autre refuse de prêter serment. La cour devient un lieu de résistance à la politique religieuse de l'Assemblée nationale.

9 Tout au long de son ouvrage, Ambrogio Caiani dépeint un Louis XVI qui, en refusant de réformer sa cour, en fait un foyer de contre-révolution qui lui nuit auprès du public et attise le radicalisme. Son argumentation est globalement convaincante. Néanmoins, elle pourrait être plus nuancée. La représentation monarchique sous Louis XVI n'est pas entièrement sclérosée. L'image du roi - bon père de famille fait ainsi florès et les souverains savent l'utiliser. De la même façon, le séjour aux Tuileries se traduit par la multiplication des visites de la famille royale aux institutions parisiennes ou aux théâtres. Louis XVI et Marie-Antoinette, certes en partie sous la contrainte, jettent les bases d'une royauté familière, plus proche de ses sujets dans ses modes de représentation. 
10 Par ailleurs, Ambroggio Caiani tend trop souvent à conclure que le roi n'a pas su faire ce qu'il aurait dû, sans analyser les raisons de la résistance de Louis XVI. Ce dernier est imbu d'une vision traditionnelle de la monarchie dont les piliers sont la souveraineté intégrale du roi et la sacralité dynastique, la cour étant la manifestation visible de ces deux piliers. Louis XVI souhaite depuis longtemps réformer sa cour, qu'il regarde comme trop coûteuse, mais il ne peut le faire que dans le cadre de cette doctrine monarchique. Or, l'assemblée nie cette dernière, ce qui sape d'emblée tout essai de compromis.

11 Aucune de ces remarques n'invalide la thèse de l'auteur ni ne met en cause la qualité d'un ouvrage stimulant qui vient combler une lacune dans l'historiographie curiale. 